\title{
Budget impact analysis of boceprevir and telaprevir for the treatment of hepatitis $C$ genotype I infection
}

This article was published in the following Dove Press journal:

ClinicoEconomics and Outcomes Research

15 November 2012

Number of times this article has been viewed

\section{Kristian Thorlund' \\ Eric Druyts ${ }^{2}$ \\ Antoine C El Khoury ${ }^{3}$ \\ Edward J Mills ${ }^{2}$}

'Department of Clinical Epidemiology and Biostatistics, McMaster University, Hamilton, ${ }^{2}$ Faculty of Health Sciences, University of Ottawa, Ottawa,

Ontario, Canada; ${ }^{3}$ Merck Sharp and

Dohme, Whitehouse Station, NJ, USA
Correspondence: Edward Mills Faculty of Health Sciences, University of Ottawa, 43 Templeton, Ottawa, Ontario, Canada, KIN 6N5

Tel +I 7783178530

Email edward.mills@uottawa.ca
Background: Boceprevir and telaprevir have recently showed dramatically better treatment outcomes than conventional PEGylated interferon plus ribavirin for the treatment of hepatitis $\mathrm{C}$ virus genotype 1, but the average cost per patient is unknown.

Methods: In the UK context, we performed a budget impact analysis to estimate the average per patient cost of adding boceprevir or telaprevir to PEGylated interferon plus ribavirin therapy. We considered both standard-duration therapy and response-guided therapy regimens of boceprevir and telaprevir for treatment-naïve and treatment-experienced patients. Our model utilized monthly discontinuation rates. We built a Bayesian Markov model to account for uncertainty associated with the clinical input and cost data.

Results: The total average cost of response-guided therapy with boceprevir is $£ 22,850$ and $£ 25,060$ for treatment-naïve and treatment-experienced patients, respectively. By comparison, the total average cost of response-guided therapy with telaprevir was $£ 29,930$ and $£ 31,880$ for treatment-naïve and treatment-experienced patients, respectively, whereas the total average cost of standard-duration boceprevir is $£ 34,680$ and $£ 34,350$ and for telaprevir was $£ 32,530$ and $£ 31,680$ for treatment-naïve and treatment experienced patients, respectively.

Conclusion: Our results demonstrate that response-guided therapy with boceprevir is notably less costly than response-guided therapy with telaprevir. Our results also suggest that the standard treatment duration of boceprevir is slightly more costly than the standard treatment duration of telaprevir.

Keywords: hepatitis C, budget impact analysis, boceprevir, telaprevir

\section{Introduction}

Two new direct-acting antivirals, boceprevir and telaprevir, have recently showed dramatically better treatment outcomes than conventional PEGylated interferon plus ribavirin for the treatment of hepatitis $\mathrm{C}$ virus (HCV) genotype $1 .{ }^{1}$ Boceprevir is a protease inhibitor that binds to the HCV nonstructural 3 active site, and telaprevir is a linear peptidomimetic HCV nonstructural 3/4A serine protease inhibitor. Both treatments have recently been approved in Europe and the US for the treatment of HCV genotype 1 infection..$^{2-4}$

The two direct-acting antivirals are both administered with the current standard of care, ie, PEGylated interferon plus ribavirin, but follow different treatment algorithms. The standard duration of boceprevir treatment is 44 weeks, where the treatment is administered from week 4 to 48 in addition to a 48 -week treatment course of PEGylated interferon plus ribavirin. Recent clinical trials have also investigated the merits for response-guided therapy, in which patients receive boceprevir from week 
4 to 24 (20 weeks) if HCV is undetectable at 8 weeks, and from week 4 to 36 (32 weeks) if $\mathrm{HCV}$ is undetectable at 24 weeks (but detectable at 8 weeks). The standard treatment duration for telaprevir is 12 weeks, where the treatment is administered from week 1 to 12 in addition to a 48-week treatment course of PEGylated interferon plus ribavirin. Recent clinical trials have also investigated the merits of telaprevir response-guided therapy, in which patients only receive PEGylated interferon plus ribavirin for the first 24 weeks if $\mathrm{HCV}$ is undetectable at 4 weeks and 12 weeks. ${ }^{1,5,6}$

A recent indirect comparison meta-analysis and a recent multiple treatment comparison meta-analysis both demonstrated that boceprevir and telaprevir as standard duration are comparable in terms of achieving a sustained virological response (SVR). ${ }^{1,5}$ These analyses also suggested that the efficacy of response-guided therapy is comparable with the efficacy of standard duration duration. ${ }^{1,5}$ However, the two direct-acting antivirals are associated with exacerbations of differing adverse events that each require different types of treatment. Boceprevir is associated with an exacerbation of anemia and neutropenia, ${ }^{1}$ the former of which may require blood transfusion or administration of erythropoietin until the blood cell count is back to normal. Telaprevir is associated with an exacerbation of rash and pruritus, ${ }^{1}$ which requires treatments such as Atarax ${ }^{\circledR}$ or hydrocortisone until the symptoms have disappeared.

In the UK, the weekly cost of boceprevir $800 \mathrm{mg}$ three times daily is $£ 700$, and the weekly cost of telaprevir $750 \mathrm{mg}$ three times daily is $£ 1866.50$. The cost of a full-length boceprevir treatment course (44 weeks) is $£ 39,800$, plus an approximate $£ 10,000$ for a 48 -week course of standard of care; thus, a total of approximately $£ 49,800$. The cost of boceprevir response-guided therapy is $£ 14,000$ (20 weeks) for early responders and $£ 22,400$ (32 weeks) for late responders, plus an approximate $£ 4000$ and $£ 6000$ for standard of care for early and late responders, respectively. Thus, the total cost is approximately $£ 18,000$ for boceprevir responseguided therapy early responders and $£ 28,400$ for boceprevir response-guided therapy late responders. The cost of a fulllength telaprevir treatment is $£ 22,398$ (12 weeks) plus an approximate $£ 10,000$ for a 48 -week course of standard of care; thus, a total of approximately $£ 32,398$. With telaprevir response-guided therapy, early responders only receive standard of care for 24 weeks (approximately £5000), and thus, the approximate total cost for telaprevir response-guided therapy in early responders is $£ 27,398$. The total cost for telaprevir response-guided therapy in late responders is the same as for the full-course treatment.
Considering the differences in the courses of treatments with standard duration and response-guided boceprevir and telaprevir, as well as the differences in handling associated adverse events, the various treatment courses with boceprevir and telaprevir are likely to have different cost profiles. Because the current clinical evidence suggests comparability in terms of efficacy, finding the least costly of the two available treatment courses is important.

The purpose of our study was to estimate and compare the average cost per patient on boceprevir and telaprevir, and to estimate and compare the cost per SVR with boceprevir, telaprevir, and standard of care treatments. We hypothesized that: the average cost per patient for responseguided boceprevir is lower than that of response-guided telaprevir; the average cost per patient for standard-duration boceprevir and telaprevir is comparable; and the average cost per SVR achieved is comparable for boceprevir, telaprevir, and standard of care. We assess these three hypotheses for both naïve and experienced patients.

\section{Materials and methods}

We performed a budget impact analysis to estimate the average cost per patient of adding boceprevir or telaprevir to standard of care for both standard-duration and responseguided regimens.

\section{Materials}

Our models used data on 4-week discontinuation rates. We contacted the authors of each published trial and industry to obtain these data. For boceprevir, detailed 4-week discontinuation rates for standard duration therapy and response-guided therapy were made available to us from two boceprevir trials. ${ }^{7,8}$ For telaprevir, these data were not made available to us; however, we were able to utilize the discontinuation data in the trial publications. In most cases, data were only available at weeks 12,24 , and $48.9^{9-14}$ We used linear interpolation to determine values at 4 -week intervals. Because we were not able to retrieve any discontinuation data on response-guided telaprevir among treatment-experienced patients, we derived these data mathematically using the available response-guided discontinuation data for telaprevir naïve-patients and response-guided boceprevir patients. We assumed the ratio between response-guided therapy discontinuation rates in naïve and experienced patients were the same for boceprevir and telaprevir. Therefore, we calculated this ratio for early responders, and separately, for late responders receiving boceprevir. We subsequently multiplied the 4-week telaprevir discontinuation rates for 
naïve patients (early and late responders separately) with the obtained ratios between discontinuation rates for naïve and experienced patients.

Our model also utilized adverse event data, ie, the proportion of patients expected to experience an adverse event common to direct-acting antivirals and standard of care treatment (ie, anemia, neutropenia, rash, and pruritus), which was derived from the indirect comparison by Cooper et al. ${ }^{1}$ Clinical data, such as the frequency of medical visits and testing required by those on treatment were also included in the model; these data were provided to us through consultations with practicing hepatologists in the US and the UK, and currently available treatment algorithms for $\mathrm{HCV} .{ }^{6}$ The costs associated with the management of adverse events and clinical monitoring were provided to us by contacting pharmacies and by interviewing practicing hepatologists and their clinic staff (data on these items were not consistently available in clinical guideline documents). MIMS UK was used to find cost data for the individual drugs (boceprevir, telaprevir, PEGylated interferon alfa-2a and alfa-2b, and ribavirin).${ }^{15}$ Finally, the rates of SVR for each treatment regimen were extracted from the indirect comparison by Cooper et $\mathrm{al}^{1}$ and the Committee on Medicinal Products for Human Use database. The individual inputs and respective data sources are presented in Table 1.

\section{Budget impact analysis models}

Our primary model is a Bayesian Markov model that incorporates uncertainty associated with the clinical input data (eg, adverse event rates). The Bayesian analyses were carried out in WinBUGS version 1.4.3 (Cambridge, UK). Our secondary model is a simplified version of our primary model built

Table I Components and data sources for the budget impact analysis

\begin{tabular}{|c|c|c|}
\hline Component & Cost & Source \\
\hline \multicolumn{3}{|l|}{ Discontinuation rates for boceprevir } \\
\hline Naïve patients & - & Poordad et $\mathrm{al}^{7}$ \\
\hline Experienced patients & & Bacon et $\mathrm{al}^{8}$ \\
\hline \multicolumn{3}{|l|}{ Discontinuation rates for telaprevir } \\
\hline \multirow[t]{2}{*}{ Naïve patients } & - & Herzode et al;"' Jacobson et al; \\
\hline & & Kumada et al; ${ }^{10}$ McHutchison et al ${ }^{12}$ \\
\hline Experienced patients & & Zeuzem et al; ${ }^{14}$ McHutchison et al ${ }^{13}$ \\
\hline \multirow[t]{2}{*}{ Proportion of early and late responders } & - & Jacobsen et al;'9 Sherman et al;'16 \\
\hline & & Marcellin et al; ${ }^{17}$ Bacon et $\mathrm{al}^{8}$ \\
\hline Proportion of SVR in each treatment group & - & Druyts et al; ${ }^{18}$ Cooper et al ${ }^{\prime}$ \\
\hline Frequency of clinical visits and medical tests & - & Clinical experts \\
\hline Frequency and proportion of adverse events & - & Cooper et al' \\
\hline Cost of boceprevir (Victrelis $\left.{ }^{\circledR}\right)$ & $£ 700 /$ week & MIMS Online ${ }^{15}$ \\
\hline Cost of telaprevir (Incivo $\left.{ }^{\circledR}\right)$ & fl866/week & MIMS Online ${ }^{15}$ \\
\hline Cost of PEGinterferon alfa-2a (PEGasys $\left.{ }^{\circledR}\right)$ & fI24/week - 80.7\% market share & MIMS Online ${ }^{15}$ \\
\hline Cost of PEGinterferon alfa-2b (ViraferonPEG ${ }^{\circledR}$ ) & £199/week - 19.3\% market share & MIMS Online ${ }^{15}$ \\
\hline Cost of ribavirin (Copegus ${ }^{\circledR}$ ) & $£ 92 /$ week - $70.1 \%$ market share & MIMS Online ${ }^{15}$ \\
\hline Cost of ribavirin $\left(\right.$ Rebetol $\left.^{\circledR}\right)$ & $£ 67 /$ week - $29.9 \%$ market share & MIMS Online ${ }^{15}$ \\
\hline Cost of clinical monitoring (average/week) & $£ 32 /$ week & Clinical experts \\
\hline Clinic visit (monthly) & $£ 40$ & \\
\hline Blood test (monthly) & $£ 100$ & \\
\hline Cost of anemia management (average per patient treated) & $£ 869$ & Clinical experts; interviews with \\
\hline Clinic visit (one initial and one follow-up) & $£ 25$ & pharmacy \\
\hline Erythropoietin treatment ( $20 \%$ of anemia patients) & $£ 250 /$ week (for 8 weeks) & \\
\hline Blood transfusion ( $5 \%$ of anemia patients) & $£ 400$ & \\
\hline Cost of neutropenia management (average per patient) & $£ 25 /$ patient treated & Clinical experts; interviews with \\
\hline Clinic visit (one initial) & $£ 25$ & pharmacy \\
\hline Cost of rash management & $£ \mid 55 /$ patient treated & Clinical experts; interviews with \\
\hline Clinic visit (one initial and one follow-up) & $£ 25$ & pharmacy \\
\hline Dermatologist visit & $£ 75$ & \\
\hline Cost of hydrocortisone I\% cream (2 months supply) & $£ 30$ & \\
\hline Cost of pruritus management & El65/patient treated & Clinical experts; interviews with \\
\hline Clinic visit (one initial and one follow-up) & $£ 25$ & pharmacy \\
\hline Dermatologist visit & $£ 75$ & \\
\hline Cost of Atarax ${ }^{\circledR}$ (25 mg capsules, 2 months' supply) & $£ 50$ & \\
\hline
\end{tabular}

Abbreviation: SVR, sustained virological response. 
in Microsoft Excel. The WinBUGS code for our primary model and the Excel spreadsheet for our secondary model are included in the Appendices.

We modeled the cost of patients over the course of treatment and follow-up using 4-week intervals for the first 48 weeks and considered the following 24 weeks (follow-up period) as one time interval. For each of the first 12 intervals, we estimated the 4-week cost of the intervention, the 4-week cost of general clinical monitoring and management, and the 4-week cost of treating adverse events. For clinical monitoring and management costs, we assumed that patients who discontinued were followed up for an additional 24 weeks after discontinuation, and thus, the proportion of patients requiring clinical monitoring or management were those still on treatment plus those who discontinued less than 24 weeks earlier. We also estimated the cost of clinical monitoring and management during the 24-week follow-up period following treatment. Using the 4-week estimates, we estimated the cumulative cost per every 4 weeks of treatment, as well as the total average cost per patient.

For our primary (Bayesian Markov) model, we used binomial probability distributions for the proportion of discontinuations, the proportion of adverse events, and the proportions of early and late responders to reflect the uncertainty associated with clinical input in the cost model. We also used binomial distributions for the proportion of SVRs in the standard of care group. However, we obtained the proportions of SVRs for boceprevir and telaprevir by applying the odds ratio estimates from a recent multiple treatment comparison. ${ }^{5}$ In this context, we used normal distributions for the corresponding log odds ratio. For all costs related to clinical monitoring and treatment of adverse events (eg, cost of visit to the general practitioner or cost of blood transfusion), we used a normal distribution with our cost estimate as the mean standard deviation equal to approximately $20 \%$ of that estimate (ie, approximately $\pm 40 \%$ equals two standard deviations).

For our primary model, we conducted Markov chain simulations based on a hypothetical cohort of 1000 patients (assuming the above depicted clinical estimates), and subsequently calculated the average costs per patient as our output. For our secondary model, ie, the Microsoft Excel spreadsheet, we used all available proportion and average cost estimates as raw inputs.

\section{Results}

Table 2 shows the total average costs and cost per SVR for response-guided therapy with boceprevir and telaprevir for

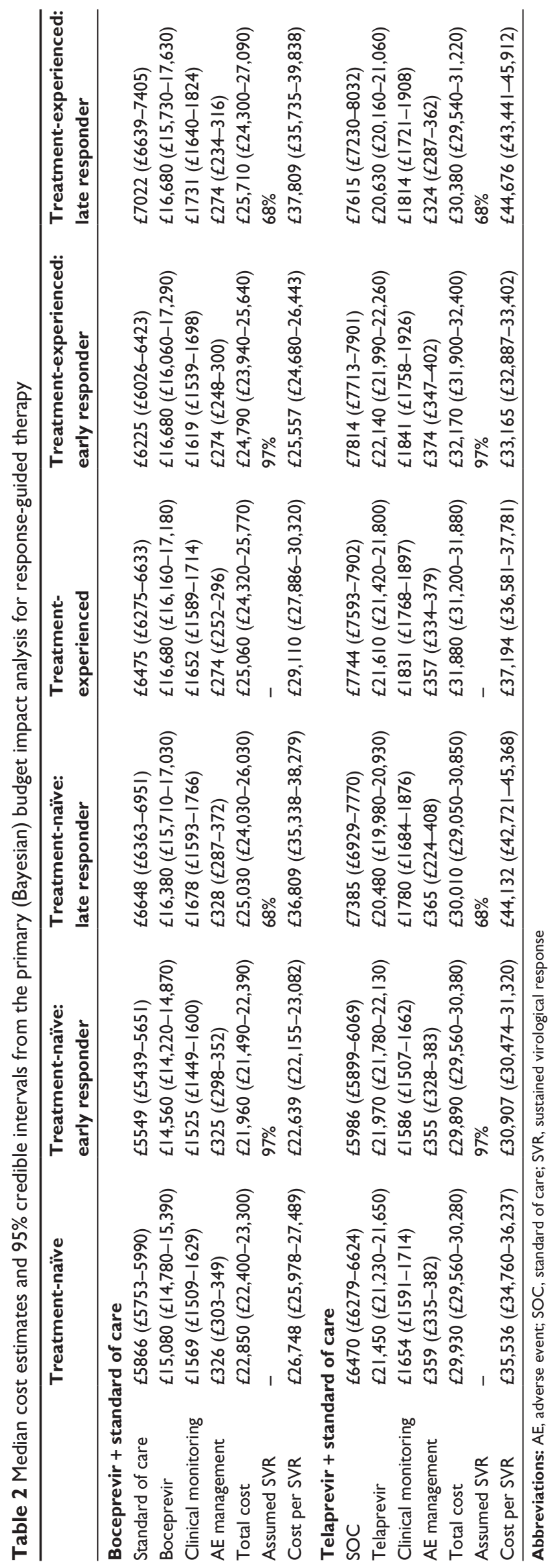


both treatment-naïve and treatment-experienced patients, as derived from our primary (Bayesian Markov) model. Note that Appendix 1 presents the same cost estimates as Table 2, but from our secondary model, the simplified Excel sheet model. Figure 1 shows the cumulative cost per patient over the treatment course and follow-up for those treated with response-guided therapy. Costs are presented separately for early and late responders, and as a weighted average for all patients receiving response-guided therapy. According to our primary model, the total average cost of response-guided therapy with boceprevir (all patients) is $£ 22,850$ (95\% credible interval [CrI] $£ 22,400-23,300)$ for treatment-naïve patients and $£ 25,060$ (95\% CrI £24,320-25,770) for treatment-experienced patients. By comparison, the total average cost of response-guided therapy with telaprevir is $£ 29,930$ (95\% CrI $£ 29,560-30,280)$ for treatment-naïve patients and $£ 31,880$ (95\% CrI $£ 31,220-32,560)$ for treatment-experienced patients. The cost per SVR with boceprevir responseguided therapy is $£ 26,748$ (95\% CrI $£ 25,978-27,489)$ for treatment-naïve patients and $£ 29,110$ (95\% CrI $£ 27,886$ 30,320 ) for treatment-experienced patients. By comparison, the average cost per SVR with telaprevir response-guided therapy is $£ 35,536$ (95\% CrI $£ 34,760-36,237)$ for treatmentnaïve patients and $£ 37,194$ (95\% CrI $£ 36,581-37,781)$ for treatment-experienced patients (see Figure 3).

Table 3 shows the total costs and cost per SVR for standard-duration boceprevir and telaprevir for both treatmentnaïve and experienced patients, as derived from our primary

\section{Average cumulative cost per treatment-naïve early responder patient}

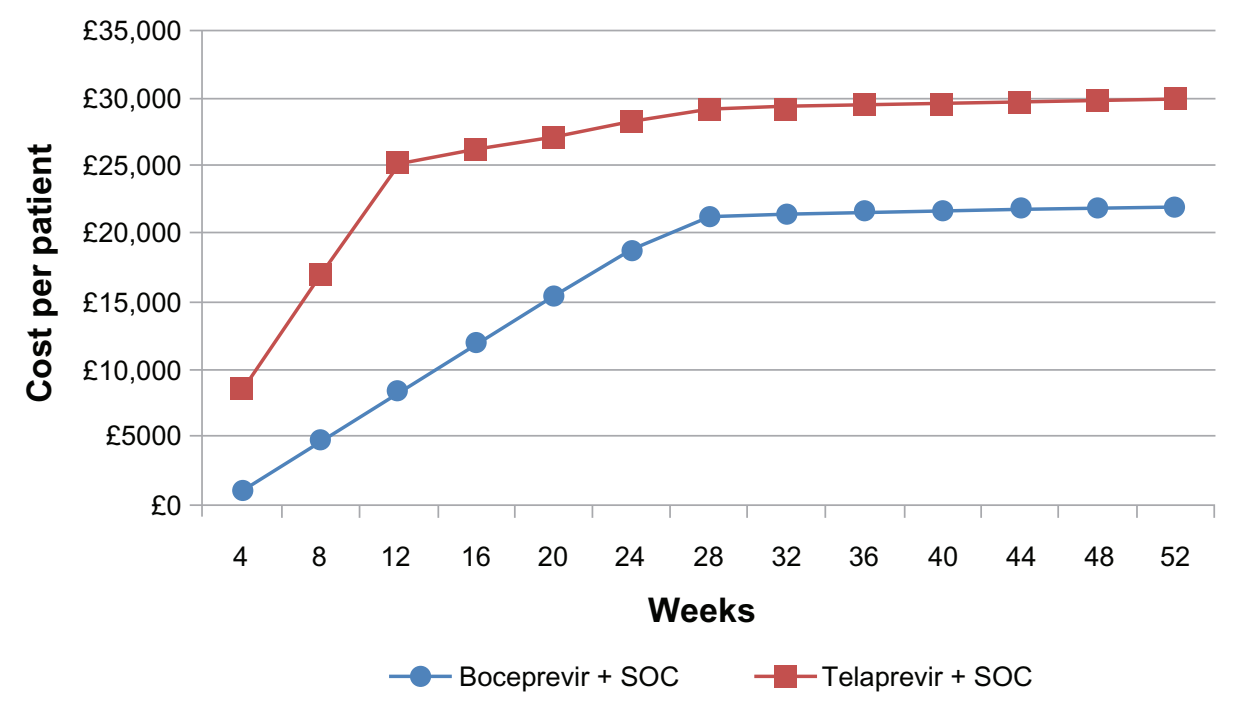

Average cumulative cost per treatment-naïve late responder patient

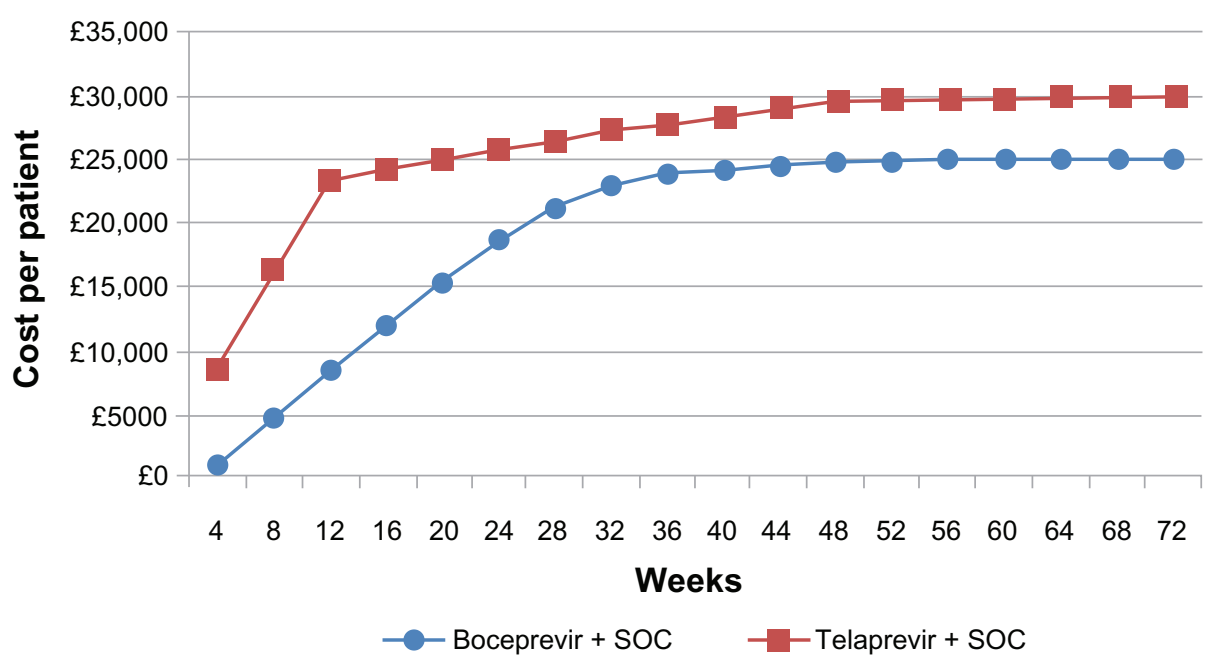

Figure I (Continued) 


\section{Average cumulative cost per treatment-experienced early responder patient}

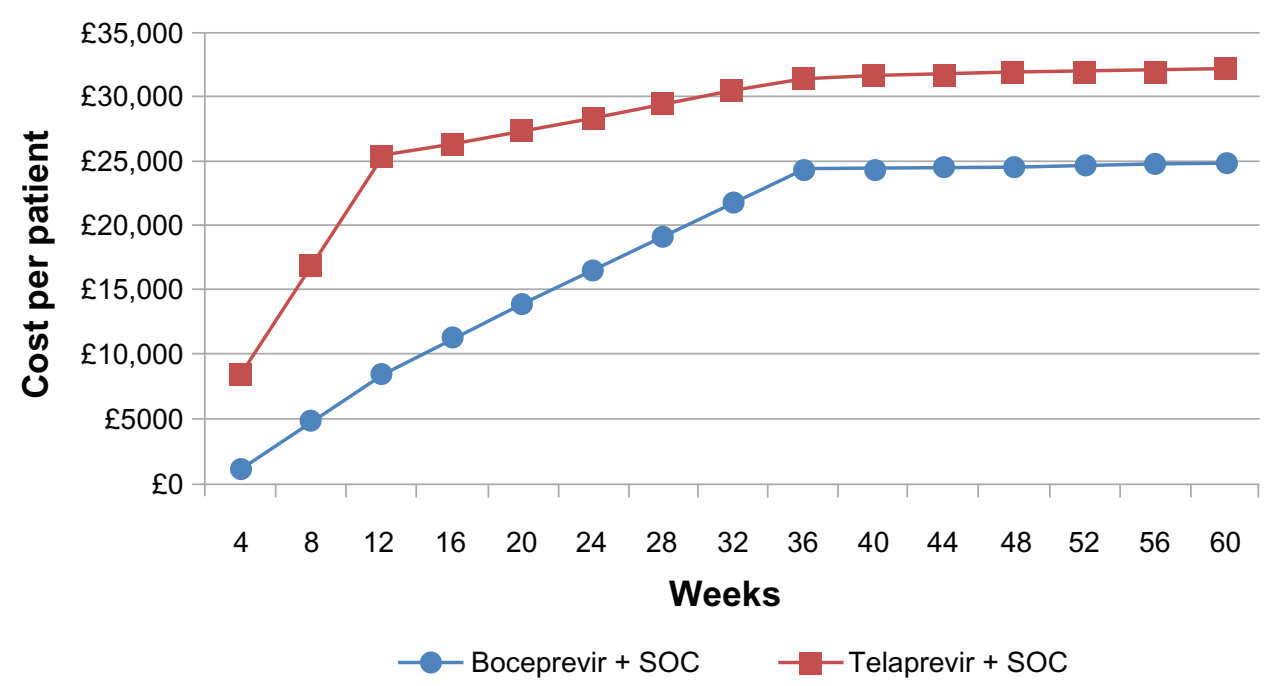

Average cumulative cost per treatment-experienced late responder patient

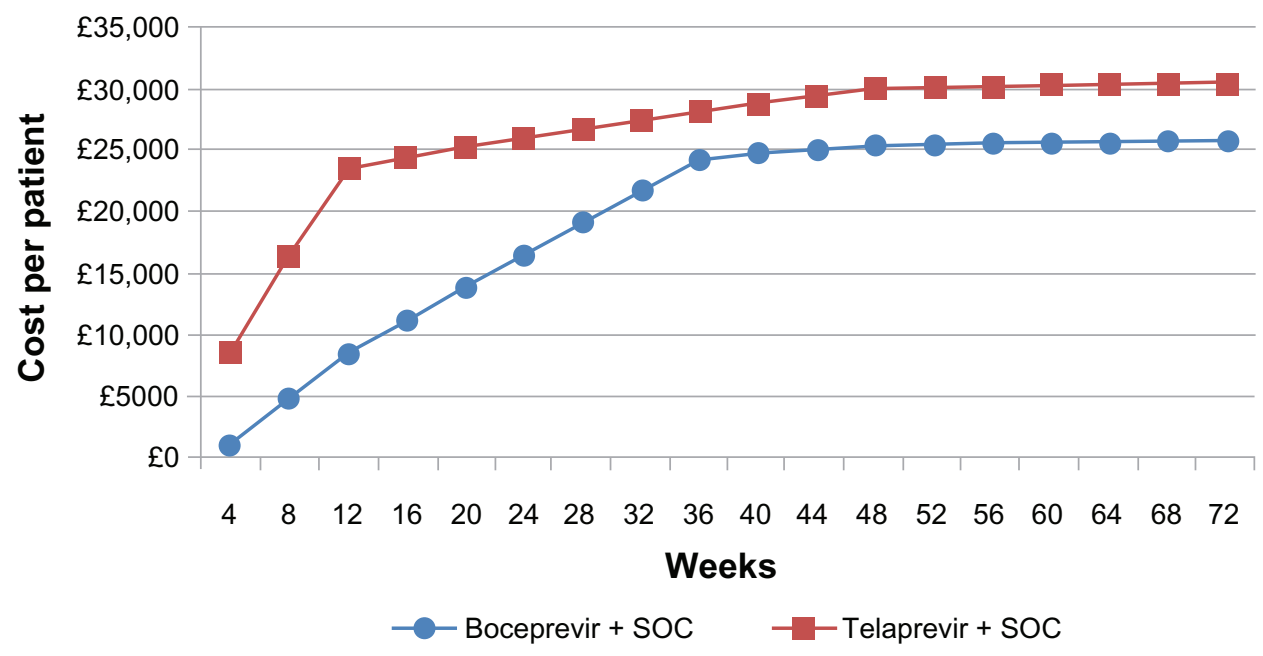

Figure I Average cumulative cost per patient treated with response-guided therapy. Abbreviation: SOC, standard of care.

(Bayesian Markov) model. Note that Appendix 2 shows the same cost estimates as Table 3 , but from our secondary model, the simplified Excel sheet model. Figure 2 presents the cumulative cost per patient over the treatment course and follow-up for those treated with a standard duration of therapy. According to our primary model, the total average cost of standard duration boceprevir is $£ 34,680$ (95\% CrI $£ 33,850-35,490)$ for treatment-naïve patients and 34,350 (95\% CrI $£ 33,390-35,260$ ) for treatment-experienced patients. By comparison, the total average cost of standard duration telaprevir is $£ 32,530$ (95\% CrI £32,160-32,880) for treatment-naïve patients and $£ 31,680$ (95\% CrI $£ 31,200$ $32,450)$ for treatment-experienced patients. The cost per SVR with standard duration boceprevir is $£ 49,540$ (95\% CrI
$£ 48,350-50,700)$ for treatment-naïve patients and $£ 49,070$ (95\% CrI £47,700-50,510) for treatment-experienced patients. By comparison, the total average cost of SVR with a standard duration of telaprevir is $£ 46,471$ (95\% CrI £45,943$46,971)$ for treatment-naïve patients and $£ 45,260$ (95\% CrI $£ 44,580-46,360$ ) for treatment-experienced patients.

Table 3 also presents the cost estimates and cost per SVR for standard of care. The total average cost of standard of care is $£ 10,010$ (95\% CrI $£ 9920-10,360)$ for treatment-naïve patients and $£ 6730$ (95\% CrI £6610-6850) for treatmentexperienced patients. The cost per SVR is $£ 25,740$ (95\% CrI $£ 24,670-26,860)$ for treatment-naïve patients and $£ 28,040$ (95\% CrI $£ 27,540-28,540)$ for treatment-experienced patients (see also Figure 3). 
Table 3 Median costs estimates and 95\% credible intervals from the primary (Bayesian) budget impact analysis for standardduration therapy

\begin{tabular}{|c|c|c|}
\hline & Treatment-naïve & Treatment-experienced \\
\hline \multicolumn{3}{|c|}{ Boceprevir + standard of care } \\
\hline soc & $£ 8527(£ 8334-87 \mid 7)$ & $£ 8467(£ 824 \mid-868 I)$ \\
\hline Boceprevir & $£ 23,880(£ 23,280-24,470)$ & $£ 23,690(£ 22,990-24,360)$ \\
\hline $\begin{array}{l}\text { Clinical } \\
\text { monitoring }\end{array}$ & $£ 1940(£ \mid 855-2027)$ & $£ \mid 933(£ \mid 848-2018)$ \\
\hline $\begin{array}{l}\mathrm{AE} \\
\text { management }\end{array}$ & $£ 332(£ 309-356)$ & $£ 265(£ 244-287)$ \\
\hline Total & $£ 34,680(£ 33,850-35,490)$ & $£ 34,350(£ 33,390-35,260)$ \\
\hline Assumed SVR & $70 \%$ & $70 \%$ \\
\hline Cost per SVR & $£ 49,540(£ 48,350-50,700)$ & $£ 49,070(£ 47,700-50,510)$ \\
\hline \multicolumn{3}{|c|}{ Telaprevir + standard of care } \\
\hline SOC & $£ 8527(£ 8334-87 \mid 7)$ & $£ 8403(£ 8 \mid 75-8628)$ \\
\hline Telaprevir & $£ 21,730(£ 21,550-21,890)$ & $£ 21,050(£ 20,810-21,290)$ \\
\hline $\begin{array}{l}\text { Clinical } \\
\text { monitoring }\end{array}$ & $£ 1940(£ \mid 855-2027)$ & $£ \mid 924(£ \mid 838-2010)$ \\
\hline $\begin{array}{l}\mathrm{AE} \\
\text { management }\end{array}$ & $£ 335(£ 3 \mid 2-357)$ & $£ 300(£ 279-317)$ \\
\hline Total & $£ 32,530(£ 32,160-32,880)$ & $£ 31,680(£ 31,200-32,450)$ \\
\hline Assumed SVR & $70 \%$ & $70 \%$ \\
\hline Cost per SVR & $£ 46,47 \mathrm{I}(£ 45,943-46,97 \mathrm{I})$ & $£ 45,260(£ 44,580-46,360)$ \\
\hline \multicolumn{3}{|c|}{ Standard of care } \\
\hline SOC & $£ 8027(£ 7850-8208)$ & $£ 5083(£ 500 I-5 I 65)$ \\
\hline $\begin{array}{l}\text { Clinical } \\
\text { monitoring }\end{array}$ & $£ \mid 870(£ \mid 790-1935)$ & $£ \mid 460(£|39|-\mid 529)$ \\
\hline $\begin{array}{l}\mathrm{AE} \\
\text { management }\end{array}$ & $£ 242(£ 223-260)$ & $€ \mid 88(£ \mid 72-205)$ \\
\hline Total & $£ 10,010(£ 9,920-10,360)$ & $£ 6730(£ 6610-6850)$ \\
\hline Assumed SVR & $38 \%$ & $24 \%$ \\
\hline Cost per SVR & $£ 25,740(£ 24,670-26,860)$ & $£ 28,040(£ 27,540-28,540)$ \\
\hline
\end{tabular}

Abbreviations: AE, adverse event; SOC, standard of care; SVR, sustained virological response.

\section{Interpretation}

In summary, the total average cost of a standard duration of treatment with boceprevir is slightly more costly than a standard duration of treatment with telaprevir, and so is the average cost per SVR. However, the total average cost of response-guided therapy with boceprevir is notably smaller than response-guided therapy with telaprevir, and so is the average cost per SVR. Moreover, the cost per SVR is comparable for response-guided therapy with boceprevir and standard of care, while the cost per SVR is more costly with telaprevir response-guided therapy.

The observed differences can be explained by the differing rates with which costs are accumulated under the different treatments. With telaprevir (both standard-duration and response-guided therapy), all patients receive the costly component of treatment, telaprevir, within the first 12 weeks. With boceprevir, patients are only given standard of care for the first 4 weeks of the treatment course, whereas the most costly component of treatment, boceprevir, is administered throughout the remaining 44 weeks (or less with response-guided therapy). With response-guided therapy in particular, the cost of boceprevir is cut dramatically, whereas the cost of telaprevir remains the same. The discontinuation rates, and thus the proportion of patients remaining on treatment, also play a role in the cost of boceprevir and telaprevir treatment. Most patients continue for 12 weeks of the full 48-week treatment course, and therefore all receive a full course of telaprevir. By contrast, patients who discontinue between weeks 12 and 48 will only receive part of the full course of boceprevir. Thus, the total average costs are typically pulled towards favoring boceprevir, because a full course of treatment is not wasted on those patients who discontinue.

The costs associated with clinical monitoring and treatment of adverse events are both relatively small compared with the costs of standard of care and boceprevir/telaprevir, and thus have little relative impact on total average cost estimates.

\section{Discussion}

We have estimated the total average cost and cost per SVR for standard duration and response-guided therapy with boceprevir and telaprevir added to standard of care, and for standard of care alone. Our results demonstrate that response-guided therapy with boceprevir is notably less costly than response-guided therapy with telaprevir, and that the cost per SVR for response-guided therapy with boceprevir is comparable with the cost per SVR for standard of care. Our results also suggest that standard-duration boceprevir is slightly more costly than standard-duration telaprevir.

Our analyses have several strengths and limitations. We have made use of the strongest clinical evidence in the form of recent results from indirect and multiple treatment comparison meta-analyses. We have also made use of detailed discontinuation data from clinical trials. Further, we interviewed several practicing hepatologists and their clinic staff members to get realistic estimates of costs, standards for adverse event treatments, and standards for clinical monitoring and management, and incorporated uncertainty surrounding our estimates through realistic probability distributions in our Bayesian model. However, the current clinical evidence remains limited because only a few trials for each of the considered treatment regimens (standard-duration and response-guided therapy) and patient groups (naïve 

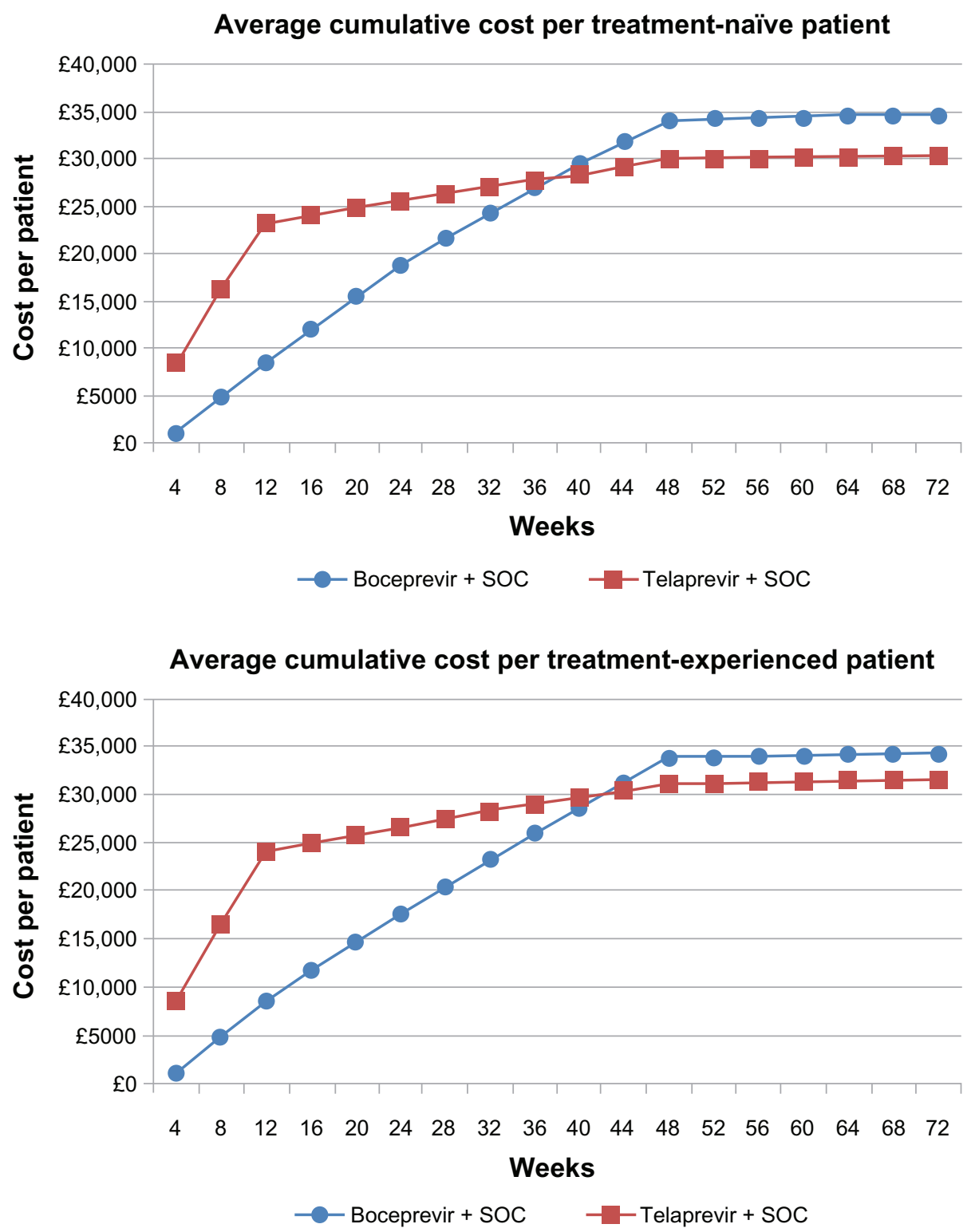

Figure 2 Average cumulative cost per patient treated with standard-duration therapy. Abbreviation: $\mathrm{SOC}$, standard of care.

and experienced) exist. Thus, our assumptions concerning comparable SVR and discontinuation rates may be challenged with emerging evidence from future clinical trials. In addition, we had access to detailed discontinuation rates only for boceprevir trials. For the modeling of adverse events, we assumed a constant relative risk within each 4-week interval. However, it is possible that this occurs with differing risks throughout the full course of treatment. For example, one could argue patients are more likely to suffer from adverse events at an early stage. However, the costs of adverse events are comparably small. Thus, it is unlikely that our results would be sensitive to deviations from the currently assumed adverse event rates.
Our results come with straightforward implications for clinical practice. Assuming that response-guided therapy is as effective as a standard duration of treatment, boceprevir added to standard of care appears to be advantageous both from a patient and societal perspective. Patients will typically prefer the most effective treatments, ie, boceprevir or telaprevir over standard of care. However, funding agencies must make decisions as to whether the additional gain in effectiveness is worth paying the additional money. In this situation, the cost of curing one patient (obtaining an SVR) is comparable with standard of care as it is with boceprevir added to standard of care. This is the case for both treatment-naïve and treatmentexperienced patients. At the same time, the resources wasted 

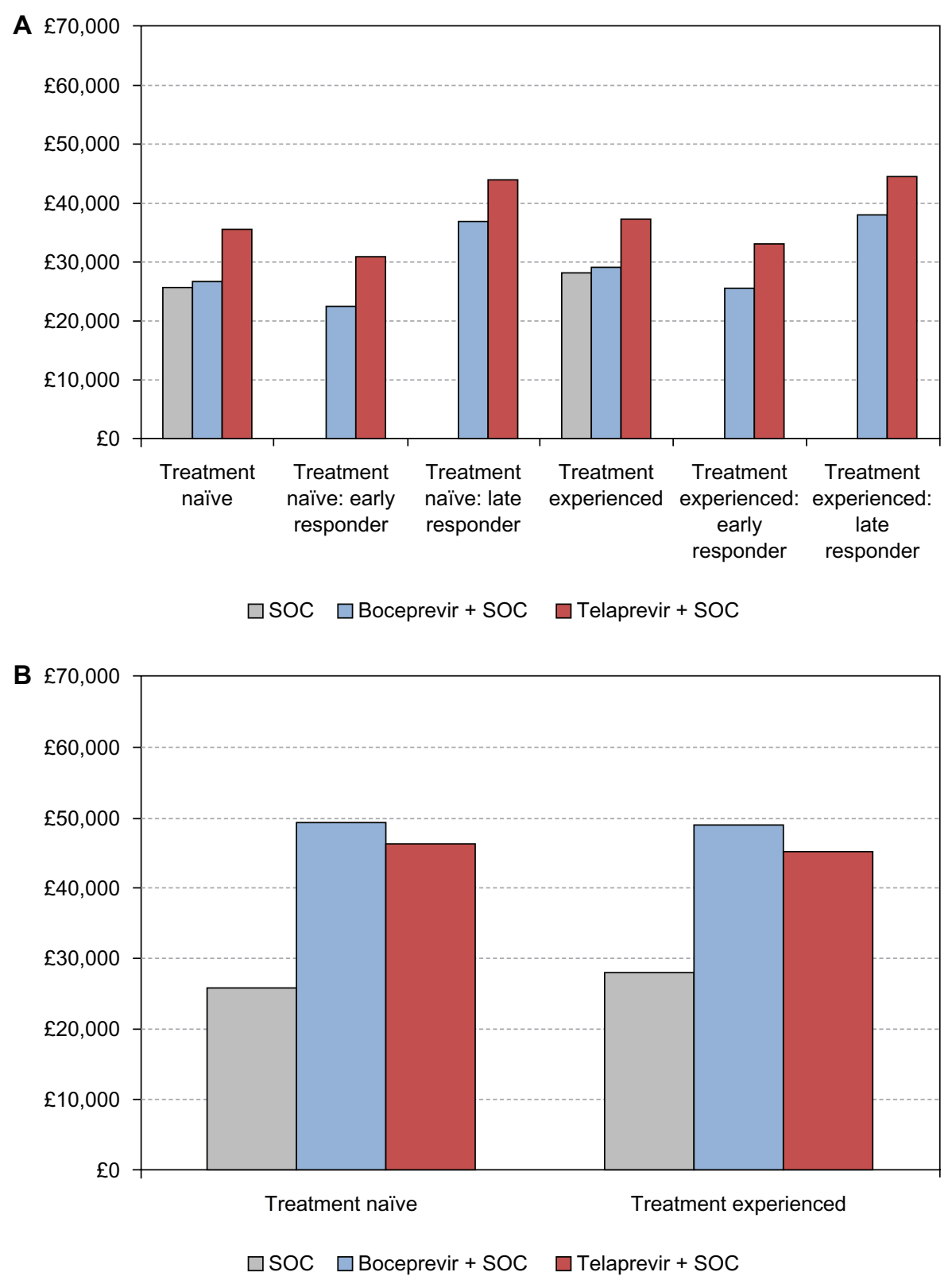

Figure 3 Cost per sustained virologic response for response-guided therapy (A) and standard-duration therapy (B).

Abbreviation: SOC, standard of care.

on providing discontinuing patients with telaprevir renders this agent an economically nonpreferable option.

\section{Disclosure}

Merck and Co funded this research based on a submitted protocol. ACEK was an employee of Merck Sharp and Dohme Corp at the time of this project and assisted with content expertise and access to data.

\section{References}

1. Cooper C, Druyts E, Thorlund K, et al. Boceprevir and telaprevir for the treatment of chronic hepatitis C genotype 1 infection: an indirect comparison meta-analysis. Ther Clin Risk Manag. 2012;8:105-130.
2. Poordad F, Khungar V. Emerging therapeutic options in hepatitis $\mathrm{C}$ virus infection. Am J Manag Care. 2011;17 Suppl 4:S123-S130.

3. Hofmann WP, Zeuzem S. A new standard of care for the treatment of chronic HCV infection. Nat Rev Gastroenterol Hepatol. 2011;8: 257-264.

4. Ciesek S, Manns MP. Hepatitis in 2010: the dawn of a new era in HCV therapy. Nat Rev Gastroenterol Hepatol. 2011;8:69-71.

5. Cooper C, Lester R, Thorlund K, et al. Direct-acting antiviral therapies for hepatitis $\mathrm{C}$ genotype 1 infection: a multiple treatment comparison meta-analysis. QJM. 2012. In press.

6. Nelson D, Jensen D, Sulkowski M. HCV clinical management resource. 2011. Available from: img.medscape.com/article/746/388/HCV_746388. pdf. Accessed October 8, 2012.

7. Poordad F, McCone J, Bacon B, et al. Boceprevir for untreated chronic HCV genotype 1 Infection. N Engl J Med. 2011;364(13):1195-1206.

8. Bacon BR, Gordon SC, Lawitz E, et al. Boceprevir for previously treated chronic HCV genotype 1 infection. NEngl J Med. 2011;364(13): 1207-1217. 
9. Jacobson IM, McHutchison JG, Dusheiko G, et al. Telaprevir for previously untreated chronic hepatitis $\mathrm{C}$ virus infection. $N$ Engl J Med. 2011;364(25):2405-2416.

10. Kumada H, Toyota J, Okanoue T, Chayama K, Tsubouchi H, Hayashi N. Telaprevir with PEGinterferon and ribavirin for treatment-naive patients chronically infected with HCV of genotype 1 in Japan. J Hepatol. 2011;56(1):78-84.

11. Hezode C, Forestier N, Dusheiko G, et al. Telaprevir and PEGinterferon with or without ribavirin for chronic HCV infection. $N$ Engl J Med. 2009;360(18):1839-1850.

12. McHutchison JG, Everson GT, Gordon SC, et al. Telaprevir with PEGinterferon and ribavirin for chronic HCV genotype 1 infection. N Engl J Med. 2009;360(18):1827-1838.

13. McHutchison JG, Manns MP, Muir AJ, et al. Telaprevir for previously treated chronic HCV infection. N Engl J Med. 2010;362(14): 1292-1303.
14. Zeuzem S, Andreone P, Pol S, et al. Telaprevir for retreatment of HCV infection. N Engl J Med. 2011;364(25):2417-2428.

15. MIMS. MIMS: Prescription drug database and drug prescribing guide. 2012. Available at: http://www.mims.co.uk/.

16. Sherman K, Flamm S, Afdhal N, et al. Response-guided telaprevir combination treatment for hepatitis $\mathrm{C}$ virus infection. $N$ Engl $J$ Med. 2011;365(11):1014-1024.

17. Marcellin P, Forns X, Goeser T, et al. Telaprevir is effective given every 8 or 12 hours with ribavirin and PEGinterferon alfa- $2 \mathrm{a}$ or- $2 \mathrm{~b}$ to patients with chronic hepatitis C. Gastroenterology. 2011;140(2):459.

18. Druyts E, Mills E, Nachega J, O'Regan C, Cooper C. Differences in clinical outcomes among hepatitis $\mathrm{C}$ genotype 1-infected patients treated with PEGinterferon alpha-2a or PEGinterferon alpha- $2 b$ plus ribavirin: a meta-analysis. Clin Exp Gastroenterol. 2012;5:11-21. 


\section{Appendices}

Appendix I Average cost estimates from the secondary (Microsoft Excel) budget impact analysis for response-guided therapy

\begin{tabular}{|c|c|c|c|c|c|c|}
\hline & $\begin{array}{l}\text { Treatment- } \\
\text { naïve }\end{array}$ & $\begin{array}{l}\text { Treatment-naïve: } \\
\text { early responder }\end{array}$ & $\begin{array}{l}\text { Treatment-naïve: } \\
\text { late responder }\end{array}$ & $\begin{array}{l}\text { Treatment- } \\
\text { experienced }\end{array}$ & $\begin{array}{l}\text { Treatment- } \\
\text { experienced: early } \\
\text { responder }\end{array}$ & $\begin{array}{l}\text { Treatment- } \\
\text { experienced: late } \\
\text { responder }\end{array}$ \\
\hline \multicolumn{7}{|c|}{ Boceprevir + standard of care } \\
\hline SOC & $£ 5641$ & $£ 5339$ & $£ 6379$ & $£ 6204$ & $£ 5985$ & $£ 6743$ \\
\hline Boceprevir & $£ 15,086$ & $f \mid 4,568$ & $€ \mid 6,355$ & $£ \mid 6,668$ & $€ \mid 6,668$ & $£ 16,668$ \\
\hline Clinical monitoring & $£ 1517$ & $£ 1500$ & $£ 1559$ & $£ 1562$ & $£ 1592$ & $£ \mid 487$ \\
\hline $\mathrm{AE}$ management & $£ 309$ & $£ 309$ & $£ 309$ & $£ 260$ & $£ 260$ & $£ 260$ \\
\hline Total & $£ 22,554$ & $£ 21,717$ & $£ 24,602$ & $£ 24,695$ & $£ 24,505$ & $£ 25,159$ \\
\hline \multicolumn{7}{|c|}{ Telaprevir + standard of care } \\
\hline SOC & $£ 6231$ & $£ 5756$ & $€ 7 \mid I I$ & $£ 7445$ & $£ 7513$ & $£ 7319$ \\
\hline Telaprevir & $£ 21,450$ & $£ 21,965$ & $£ 20,494$ & $£ 21,606$ & $£ 22,139$ & $£ 20,617$ \\
\hline Clinical monitoring & $£ \mid 640$ & $£ 1594$ & $£ 1726$ & $£|8| 4$ & $£ \mid 855$ & $£ 1739$ \\
\hline $\mathrm{AE}$ management & $£ 317$ & $£ 317$ & $£ 315$ & $£ 288$ & $£ 289$ & $£ 287$ \\
\hline Total & $£ 29,638$ & $£ 29,633$ & $£ 29,647$ & $£ 31,154$ & $£ 31,796$ & $£ 29,962$ \\
\hline
\end{tabular}

Abbreviations: AE, adverse event; SOC, standard of care.

Appendix 2 Average cost estimates from the secondary (Microsoft Excel) budget impact analysis for standard-duration therapy

\begin{tabular}{|c|c|c|}
\hline & Treatment-naïve & Treatment-experienced \\
\hline \multicolumn{3}{|c|}{ Boceprevir + standard of care } \\
\hline SOC & $€ 8191$ & $€ 8145$ \\
\hline Boceprevir & $£ 23,848$ & $£ 23,696$ \\
\hline Clinical monitoring & $£ 1898$ & $£ 1902$ \\
\hline $\mathrm{AE}$ management & $£ 524$ & $£ 428$ \\
\hline Total & $£ 34,461$ & $£ 34,|7|$ \\
\hline \multicolumn{3}{|c|}{ Telaprevir + standard of care } \\
\hline SOC & $€ 7764$ & $£ 8082$ \\
\hline Telaprevir & $£ 20,382$ & $£ 21,054$ \\
\hline Clinical monitoring & $£ 1858$ & $£ 1890$ \\
\hline $\mathrm{AE}$ management & $£ 466$ & $£ 412$ \\
\hline Total & $£ 30,470$ & $£ 31,438$ \\
\hline \multicolumn{3}{|l|}{ Standard of care } \\
\hline SOC & $£ 7263.62$ & $£ 4870.81$ \\
\hline Clinical monitoring & $£ \mid 746.68$ & $£ \mid 380.70$ \\
\hline $\mathrm{AE}$ management & $£ 325.00$ & $£ 283.71$ \\
\hline Total & $£ 9335.30$ & $£ 6535.22$ \\
\hline
\end{tabular}

Abbreviations: $\mathrm{AE}$, adverse event; SOC, standard of care.

\section{Publish your work in this journal}

ClinicoEconomics \& Outcomes Research is an international, peerreviewed open-access journal focusing on Health Technology Assessment, Pharmacoeconomics and Outcomes Research in the areas of diagnosis, medical devices, and clinical, surgical and pharmacological intervention. The economic impact of health policy and health systems organization also constitute important areas of coverage. The manuscript management system is completely online and includes a very quick and fair peer-review system, which is all easy to use. Visit http://www.dovepress.com/testimonials.php to read real quotes from published authors. 